\title{
A orillas del Pirgua. Representaciones rupestres en el sitio Río Pirgua 1 (Guachipas, Salta)
}

M. Pía Falchi*, Marcelo A. Torres* y Lucía A. Gutiérrez*
Recibido: 16 de febrero de 2017

Aceptado:

17 de julio de 2017

\section{Resumen}

El departamento de Guachipas, Salta (Noroeste Argentino) se caracteriza por la concentración de sitios arqueológicos, algunos de ellos se destacan por sus representaciones rupestres. En esta presentación se describe el sitio Río Pirgua 1 y se comparan sus representaciones con las de otros sitios de la microrregión Las Juntas. El conjunto analizado se compone de 96 motivos pintados que incluyen escutiformes (característicos del área de estudio), figuras humanas y camélidos en diferentes actitudes. Los mismos serían producto de tres momentos de ejecución. El más reciente posiblemente coincidente con la presencia inca en la región (1450-1535 d.C.), otro momento atribuido al período Desarrollos Regionales (900-1450 d.C.) y uno más temprano correspondiente al primer milenio de la era cristiana (0-900 d.C.). Se discuten las razones de esta adscripción.

\section{On the riverside of the Pirgua: rock art from the Río Pirgua 1 site (Guachipas, Salta)}

\begin{abstract}
The department of Guachipas, Salta (Northwestern Argentina) is characterized by a concentration of archaeological sites, some of them standout because of their rock art. In this article, the Río Pirgua 1 site is described, with its rock art being compared with that from other sites in the Las Juntas micro-region. The analyzed set consisted of 96 painted motifs that included shield-shape motifs (characteristic of this area), human figures and camelids in different poses. These representations were the product of three phases of conception. The most recent coinciding with the Inca presence in the region (A.D. 1450-1535), another phase dating to the Regional Developments Period (A.D. 900-1450), and an earlier one corresponding to the first millennium of the Christian era (A.D. 0-900). Here we discuss these temporal adscriptions.
\end{abstract}

* Instituto Nacional de Antropología y Pensamiento Latinoamericano (INAPL). 3 de febrero 1378 (CP C1426BJN) Ciudad Autónoma de Buenos Aires, Argentina. E-mail: mpiafalchi@yahoo.com.ar; marcel_art@yahoo.com.ar; luciagutierrez94@gmail.com

\section{Keywords}

Rock art Execution sequence Guachipas Northwestern Argentina 


\section{Introducción}

En este trabajo se aborda el análisis de un sitio en particular, Río Pirgua 1 (RP1), que se incluye en el extenso inventario de sitios arqueológicos del departamento de Guachipas, en el cual se reconoce la microrregión de Las Juntas, provincia de Salta, Noroeste Argentino (NOA). Esta área es reconocida por la concentración de sitios con representaciones rupestres entre los que se destacan en el sector norte la quebrada de Ablomé y más al sur el Cerro Cueva Pintadas (CCP), Las Planchadas, la gruta pintada de El Lajar y la famosa gruta de Carahuasi (Ambrosetti, 1895; Aparicio, 1944; de Hoyos, 2012; Podestá, Rolandi y Sánchez Proaño, 2005; Podestá et al., 2016a; Podestá, Re, Romero y Rolandi, 2016b; Quiroga, 1931; Rolandi, Podestá, Sánchez Proaño y Re, 2002; Santillán, 1991; entre otros). En trabajos anteriores (Falchi, en prensa; Podestá et al. 2013, 2016a, 2016b) se consideró a Guachipas como mircrorregión pero la misma abarcaba un espacio demasiado amplio. Con el avance de las investigaciones se han redefinido las áreas de interacción como territorios acotados espacialmente vinculados a actividades cotidianas. De esta manera, se define Guachipas como una subregión dentro de la región del valle de Lerma, y a su vez, dentro de la misma se consideran varias microrregiones (por ejemplo, Ablomé, Las Juntas y Pampa Grande).

Las pinturas rupestres de Río Pirgua 1 constituyen un registro arqueológico poco conocido que se encontraba inédito y carecía de trabajos integradores con el resto de los sitios de la microrregión Las Juntas. El objetivo de este trabajo es presentar la documentación y análisis completo de las pinturas, además de establecer su secuencia de ejecución, a fin de contribuir a la comprensión de las características de las ocupaciones humanas prehispánicas en la mencionada área. Asimismo, se busca entender el proceso de pintado a lo largo del tiempo en este sitio dando importancia a la diacronía observable en el arte rupestre.

\section{Antecedentes}

Desde el año 1998, dentro del marco del Programa de Documentación y Preservación del Arte Rupestre Argentino (DOPRARA-INAPL), se vienen realizando estudios sobre las representaciones rupestres de Guachipas, ubicada en el centro de la provincia de Salta, NOA (Figura 1). Inicialmente, las investigaciones se focalizaron en el estudio del Cerro Cuevas Pintadas (CCP) en el cual se localizaron 44 aleros con representaciones rupestres (Rolandi et al., 2002; Santoni y Xamena, 1995). Posteriormente se incluyeron otros sitios como la gruta pintada de El Lajar, Carahuasi, Las Planchadas y varios aleros ubicados en la quebrada de Ablomé, ésta última al Norte del departamento (Alonso, Navamuel y Tarruselli, 2000; de Hoyos, 2012; Falchi, en prensa; Podestá et al., 2013, 2016b).

En el área predominan los afloramientos de areniscas rojizas del subgrupo Pirgua (grupo Salta) (Alonso et al., 2000), las cuales conforman casi la totalidad de los soportes de las representaciones. Estos se ubican en serranías escarpadas y cadenas montañosas separadas por valles profundos entre los que se cuentan el Calchaquí, por el Oeste y el de Lerma, por el Norte, que a su vez forman parte de la cordillera Oriental.

\section{Área de estudio}

Con el fin de sistematizar el registro y estudio de los diversos sitios con arte rupestre, el área fue sectorizada del siguiente modo: hacia el Norte, la microrregión quebrada de Ablomé, actualmente adyacente al gran espejo de agua conformado por el dique Cabra Corral y, hacia el sur, la microrregión Las Juntas separada de la anterior por $40 \mathrm{~km}$ 


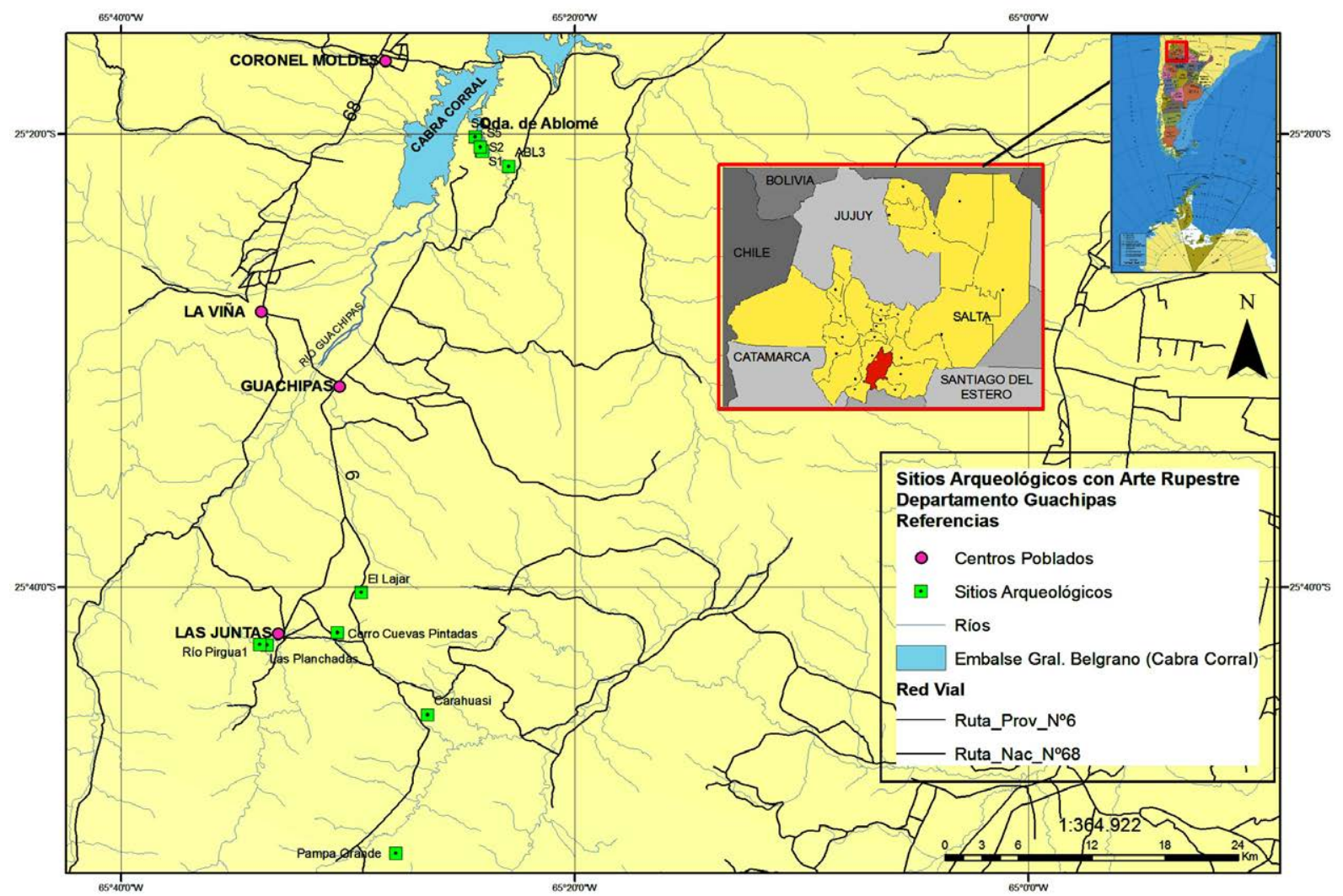

Figura 1. Ubicación de los sitios mencionados.

aproximadamente (Figura 1). Ambas presentan una vegetación variada que responde a diferencias altitudinales. El ambiente tiene la influencia de las tres ecorregiones que caracterizan el sur de la provincia de Salta: las Yungas, los bosques del Chaco Seco y el Monte de Llanuras y Bolsones. En algunos sectores dominan las plantas xerófilas con pastos duros que forman amplias praderas alternadas con isletas de arbustos. En los lugares más reparados se observa crecimiento arbóreo, además de matas de helechos y bromelias. Por ejemplo, para acceder a los sitios próximos a Las Juntas se atraviesa una cuesta con importante presencia del cebil (Anadenanthera colubrina, var. cebil). Río Pirgua 1 ( $1.800 \mathrm{~m}$ s.n.m.) se ubica en la localidad Las Juntas que cuenta con la mayor cantidad de sitios con representaciones rupestres del área cuyo centro es CCP (Podestá et al., 2013, 2016a). Este sitio se localiza en una barranca a orillas del río Pirgua, a 6 $\mathrm{km}$ de CCP y a menos de $1 \mathrm{~km}$ de Las Planchadas (Figura 2).

\section{El sitio Río Pirgua 1}

En 1991 Luis Santillán realiza un informe de campaña para la dirección de Patrimonio de la provincia de Salta en el cual da cuenta de varios sitios. En el sector denominado "río abajo del Pirgua" documenta un sitio con arte rupestre (R1). El informe incluye una breve descripción del alero, dos fotos y tres calcos. En sus conclusiones, propone que las representaciones de escudos y auquénidos son similares a las de otros sitios de Guachipas asignados al período Agroalfarero Tardío (1000-1500 d.C.) (Santillán, 1991:10). Por su parte, de Hoyos (2012) se refiere al alero como Biscolar y realiza una descripción de las representaciones centrándose en el análisis de las figuras humanas. 


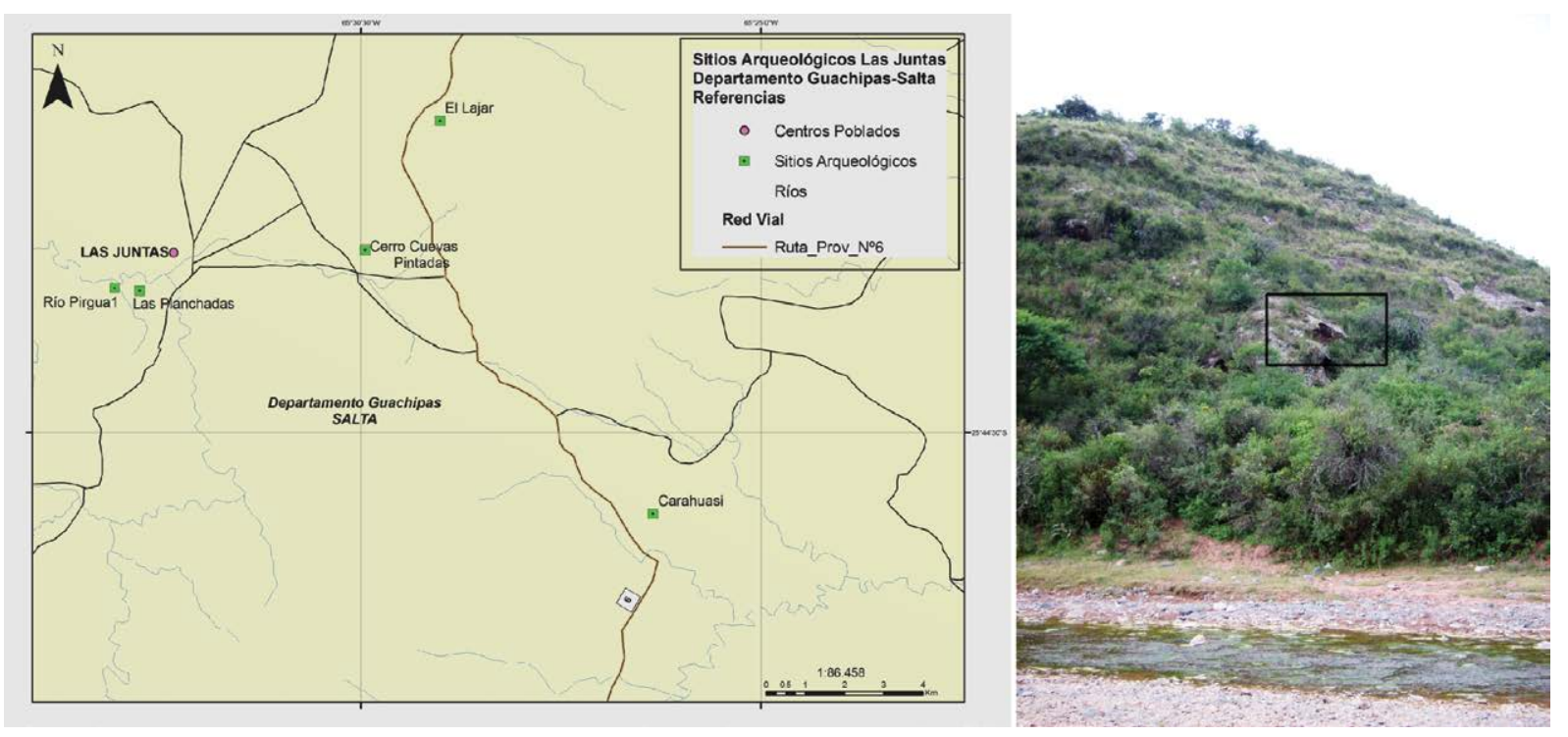

Figura 2. Detalle de ubicación del sitio Río Pirgua 1 (RP 1).

El equipo del INAPL llegó al sitio en el año 2014 acompañado por pobladores locales que insistieron en la necesidad de su documentación. Se identificaron tres aleros, solo uno con representaciones rupestres (Figura 2). Río Pirgua les un alero con orientación SE, tiene 3,90 m de ancho, 1,70 m de alto y 1,10 $\mathrm{m}$ de profundidad y su superficie de reparo es de $2 \mathrm{~m}^{2}$. La roca soporte es arenisca roja y se encuentra afectada por agentes de deterioro naturales entre los cuales se registran líquenes y musgos, telas de araña, acreciones minerales blancas, exfoliaciones y grietas horizontales. Asimismo, se detectan intervenciones antrópicas como rayados y frotaduras de ganado vacuno.

\section{Materiales y métodos}

En el primer trabajo de documentación se tomaron fotografías digitales del conjunto de las representaciones y en detalle utilizando escala IFRAO, se realizaron dibujos a mano alzada en papel milimetrado y se confeccionó un primer inventario de motivos. Las tareas en laboratorio incluyeron la aplicación de filtros de color con el programa ImageJ D-Stretch (Harman, 2008), el procesamiento de las imágenes en Adobe Photoshop para la elaboración de calcos digitales y la confección de una ficha Excel para el inventario y obtención de datos estadísticos. En el año 2016 se documentó nuevamente el sitio y se concluyó con su registro corrigiendo el dibujo a mano alzada. Asimismo se identificaron los colores de las representaciones según el catálogo Munsell Soil Color Chart (2010). Nuevamente se tomaron fotografías para evaluar los procesos de deterioro que afectan al sitio.

\section{Categorías y tipos de motivos. Tonalidades}

La totalidad de los 96 motivos registrados en Río Pirgua 1 son pinturas, de los cuales 58 motivos son figurativos $(60,42 \%), 17$ son abstractos $(17,71 \%)$ y 21 son indeterminados por deterioro $(21,88 \%)$. Los motivos simples $(n=69)$ predominan sobre los compuestos $(\mathrm{n}=27)$. Se ha considerado como motivos simples a aquellas representaciones ejecutadas sin diferenciación técnica mediante un trazo aparentemente unitario y como motivos compuestos a aquellas que estén constituidas por dos o más elementos vinculados entre sí por razones morfológicas o de contenido (Gradin, 1978).

Dentro de los motivos figurativos los zoomorfos representan el 55,17\% ( $\mathrm{n}=32)$, esta categoría incluye los tipos: camélido aislado $(\mathrm{n}=14)$, camélidos agrupados $(\mathrm{n}=10)$, 
camélidos alineados $(\mathrm{n}=4)$, zoomorfo indeterminado $(\mathrm{n}=3)$ y felino $(\mathrm{n}=1)$. Por su parte, los escutiformes componen el $31,03 \%(n=18)$, estos se presentan con atributos humanos $(\mathrm{n}=7)$ y $\sin$ atributos humanos $(\mathrm{n}=11)$. Las figuras humanas constituyen el $5,17 \%(n=3)$ de los motivos figurativos. Los tres casos incluyen uno con atributos de jerarquía y dos sin ellos. Se ha hecho esta distinción cuando las figuras humanas presentaban tocados, tobilleras o armas. Asimismo, se han registrado cinco escenas $(8,62 \%)$. Las mismas son motivos figurativos compuestos en los que se puede percibir alguna acción y que proporcionan valoración sobre ciertas actividades (Aschero, 1988). Se incluyen dos casos de escena de caza, un caso de cópula de camélidos y dos ejemplos de figuras humanas guiando camélido (Figura 3).

La totalidad de los motivos abstractos son lineales. Se destacan las líneas rectas $(\mathrm{n}=$ $5)$, quebradas $(n=4)$, trazos $(n=6)$ y líneas curvas $(n=2)$ (Figura 3$)$.

Con respecto al uso del color predominan las monocromías $(\mathrm{n}=83 ; 86,46 \%)$ sobre las bicromías $(\mathrm{n}=12 ; 12,50 \%)$, observándose solo un caso de policromía $(\mathrm{n}=1 ; 1,04 \%)$. Los colores registrados según el catálogo Munsell Soil Color Chart (2010) son: rojo claro (10R 6/8), rojo pálido (10R 7/4), rosa (5YR 8/3), blanco (10R 8/1), blanco rosado (10R $8 / 2$ ), gris rojizo (10R 5/1), gris rojizo oscuro (10R 3/1).

\section{Escutiformes, figuras humanas y camélidos}

Al igual que en otros sitios de Guachipas, los escutiformes en RP1 se presentan con y sin atributos humanos. En los casos que se observan atributos humanos pueden mencionarse ejemplos de cabezas, pies, tocados y seis casos de armas (un caso de hacha con adornos y los otros de lanzas). En cuanto a su tratamiento, se registran cuatro de tratamiento lineal de contorno y los restantes 14 de tratamiento plano. No se han identificado ejemplos de complejos tocados de plumas como en otros sitios del área (Podestá et al., 2013; Santoni y Xamena, 1995).

En RP1 estos motivos se pueden reunir en dos tipos. Por un lado, escutiformes medianos (hasta $10 \mathrm{~cm}$ de alto sensu Podestá et al., 2013) de técnica muy cuidada en tonalidad gris oscura, blanca, un caso de bicromía rojo/gris oscura. Se pintaron con mezcla pigmentaria fluida y un instrumento capaz de lograr terminaciones muy finas (trazos de 0,5 cm). Estos motivos se asocian con camélidos agrupados en las mismas tonalidades y con una escena de caza en la que participa un felino junto a otros zoomorfos. Otro caso, la única tricromía del sitio, se presenta en rojo amarillo y gris oscuro. Este ejemplo se destaca por portar un hacha de tonalidad roja con apéndices negros a modo de adornos en su empuñadura. Sin embargo, también se ha registrado un tipo de escutiforme más grande, de factura más descuidada de tonalidad blanca más brillante, superpuesto a un motivo de camélido (ver más adelante).

Las figuras humanas se observan aisladas o participando de escenas de tiro o de caza de camélidos. En un caso de escena de caza, a pesar de su tamaño reducido (de 2 a $5 \mathrm{~cm}$ de alto cada figura), los personajes presentan detalles de tobilleras y un caso de tocado. Se destaca un caso de antropomorfo con uncu que luce tocado y arma.

Por su parte los camélidos se presentan en tres morfologías. En primer lugar, camélidos de perfil con dos patas, sin indicación de autopodio de tamaño muy pequeño $(3 \mathrm{~cm}$ de alto y $3 \mathrm{~cm}$ ancho cada uno). Este diseño se presenta en ejemplares aislados (camélido), en fila (camélidos alineados) o formando conjuntos (camélidos agrupados) en los que pueden registrarse desde dos hasta 25 individuos (Figura 3). Entre estos últimos pueden observarse casos de camélidos monocromos acompañando camélidos bicromos (gris, blanco y gris-blanco) y casos de conjuntos de camélidos monocromos (gris, blancorosado, rosa o rojo pálido). Cabe mencionar que un conjunto incluye un motivo que 


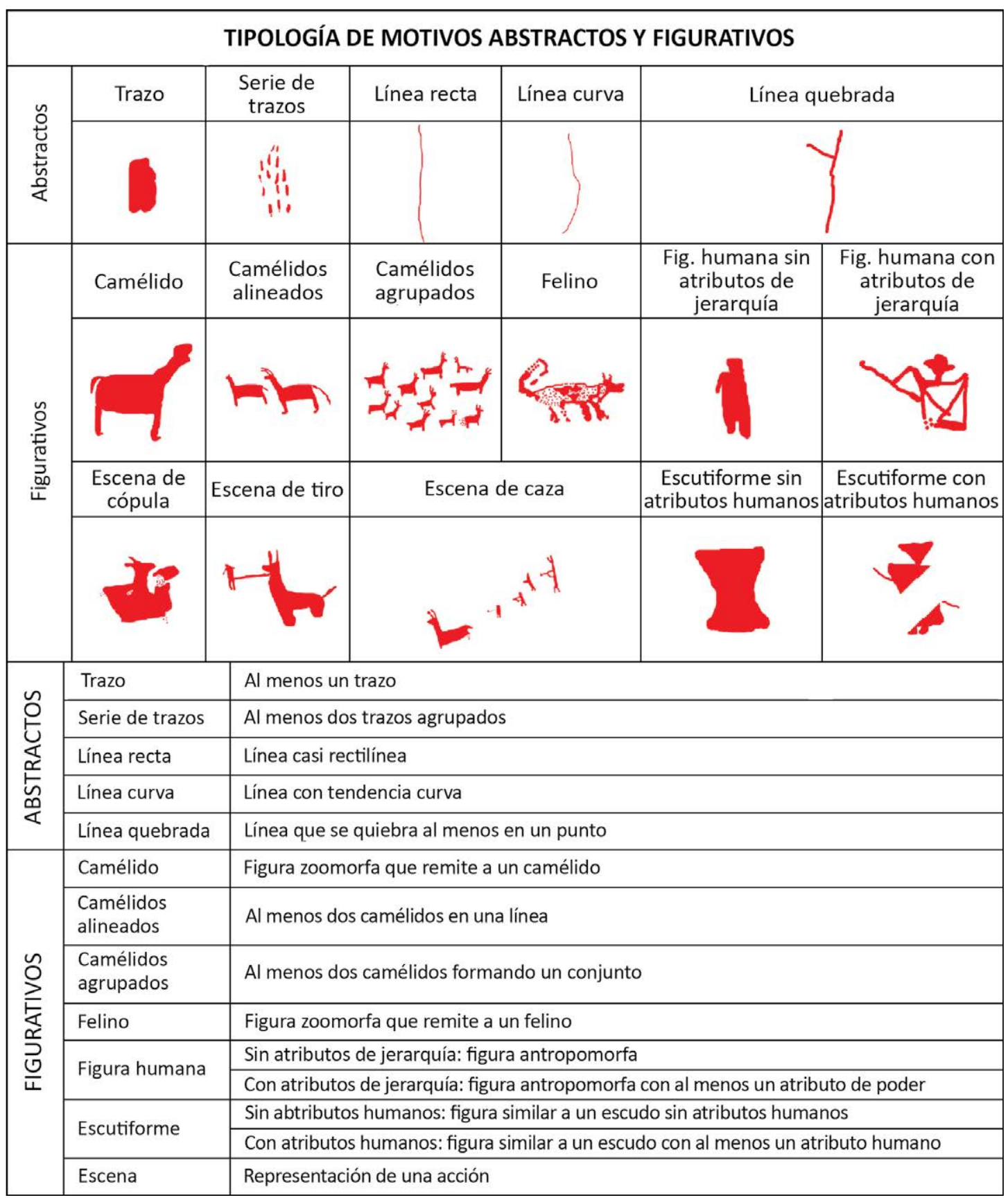

Figura 3. Tipología de motivos abstractos y figurativos Río Pirgua 1 (RP 1).

se interpreta como una escena de cópula y un camélido con indicación de atadura. Los casos de camélidos alineados son monocromías. En todos los ejemplos se utilizan las mismas tonalidades y mezcla pigmentaria fluida que para los escutiformes, las figuras humanas y los motivos abstractos.

El segundo diseño registrado son camélidos esquemáticos de tres o cuatro patas, dos orejas, trazo grueso, mezcla pigmentaria espesa de tonalidad blanca de tamaño mediano (10 cm de alto y $10 \mathrm{~cm}$ de ancho cada uno). La misma solo se presenta en un caso de dos camélidos alineados. Un escutiforme se encuentra claramente superpuesto a este motivo de camélidos (Figura 4). 

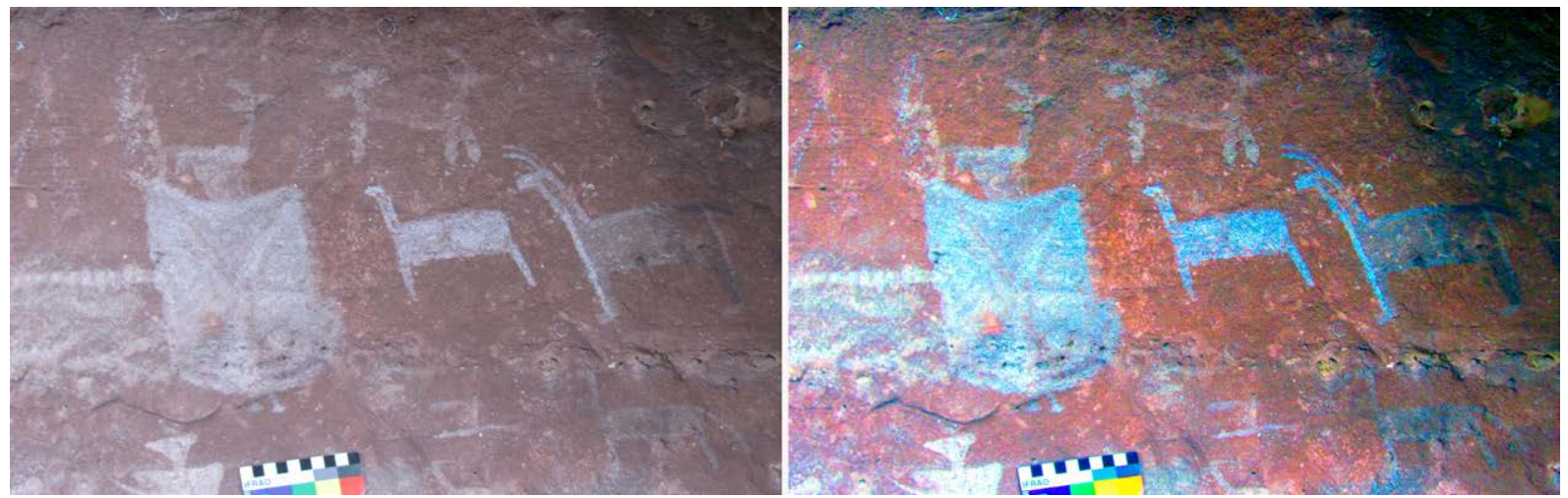

Figura 4. Superposición de escutiforme de tonalidad blanca sobre camélido de cuatro patas asociado al primer milenio (RP 1) y camélidos con indicación de autopodios tentativamente asignados al período Inca. DStretch, canal lab.

La tercera morfología encontrada en RP1 incluye camélidos de cuerpo rectangular, con el contorno delineado, cola larga, orejas vueltas hacia adelante y un caso de indicación de autopodio. Estos camélidos se presentan en la misma tonalidad blanca que el escutiforme involucrado en la superposición antes mencionada. Los camélidos, el escutiforme y una escena de tiro ubicada a $20 \mathrm{~cm}$ de estos motivos muestran señales de haber sido repintados o reciclados.

\section{Secuencia de ejecución}

Como resultado del análisis de la variabilidad de diseños de figuras de camélidos, las superposiciones, los indicadores iconográficos-estilísticos que se detallan en el próximo acápite y la comparación con sitios de Las Juntas (especialmente Las Planchadas donde recientemente Podestá y colaboradoras (2016b) han establecido una cronología de ejecución de las pinturas) y de otras localidades cercanas, se propone que las representaciones rupestres de RP1 corresponden al menos a tres momentos de ejecución.

Se han registrado tres superposiciones de motivos. La primera superposición involucra una serie de trazos negros sobre un camélido del mismo tono, debido a la similitud de la tonalidad entre ambos motivos podría interpretarse como una ejecución sincrónica. La segunda y la tercera incluyen un escutiforme con atributos humanos (cabeza y pies, con lanza) y camélido blanco de cola larga, ambos sobre un motivo de camélidos agrupados de tono rosado y sobre un escutiforme muy desvaído. A continuación se presentan en forma ordenada cronológicamente los tres momentos de ejecución propuestos.

\section{Primer Milenio (0-900 d.C.)}

A este período solo se adscriben los dos camélidos alineados de cuatro patas, cuerpo lineal y dos orejas, ubicados a la derecha del soporte. Este tipo de camélidos se ha registrado en CCP con las mismas características técnicas (mezcla pigmentaria espesa, de tonalidad blanco, de trazo grueso) formando un conjunto con una figura humana "en bloque" con cetros asociadas al Formativo Temprano (Aschero, 2007), cruz de contorno curvilíneo y motivos de laberintos (Figura 5). Asimismo, en las excavaciones y recolecciones realizadas hasta el momento en CCP se ha recuperado cerámica gris incisa regionalmente asociada a ocupaciones del primer milenio (Podestá et al., 2016a). Se ha mencionado más arriba la superposición de escutiforme sobre camélidos esquemáticos. 


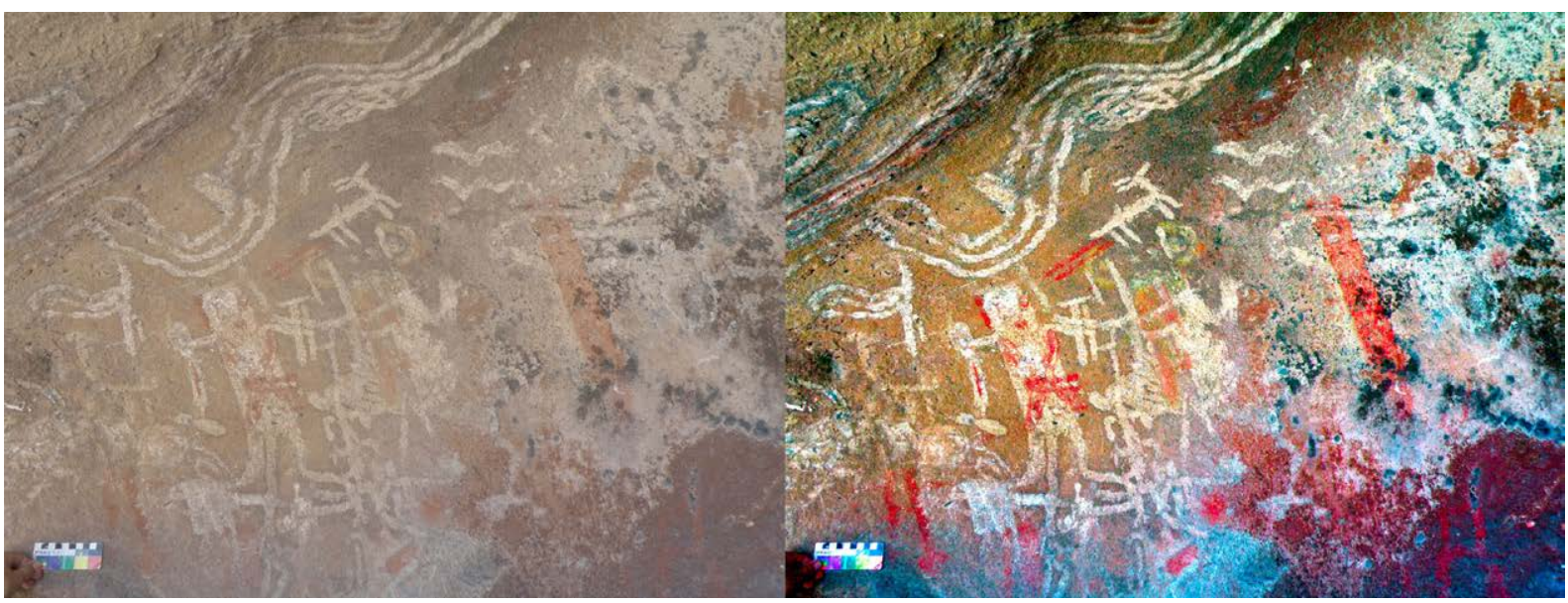

Figura 5. Figura humana en bloque asociada a camélido de cuatro patas, cruz de contorno curvilíneo y motivos de laberintos asociados al primer milenio (Cerro Cuevas Pintadas, alero 8). DStretch, canal lab.

En la cercana microrregión de Cafayate se han relacionado representaciones de camélidos de iguales características morfológicas y figuras humanas con cetros con el Formativo Inferior en términos de las autoras Ledesma y Subelza (2009). Cabe mencionar que en el sitio Las Planchadas no se han descripto motivos que puedan adscribirse a este momento.

\section{Periodo de Desarrollos Regionales (900-1450 d.C.)}

Las representaciones de camélidos, salvo los casos descriptos (los esquemáticos y los delineados o reciclados), se adscriben a este momento (Figura 6). Como ya se adelantó son de tamaño muy pequeño, de cuerpo rectangular con una o dos orejas apenas insinuadas vueltas hacia atrás, dos patas (una trasera y una delantera), en actitud estática. En las mismas tonalidades (gris oscuro y blanco) se registran trazos alineados y agrupados. A este período corresponderían la mayoría de las representaciones de RP 1 que están dispuestas sobre todo el soporte disponible de este pequeño alero.

La representación de camélidos agrupados y alineados es coherente con la idea de que durante el período de Desarrollos Regionales, dada las aptitudes ambientales de disponibilidad de agua y pasturas de la microrregión Las Juntas, los grupos humanos del pasado hayan basado su economía en la práctica pastoril y posiblemente caravanera (Podestá et al., 2016a).

Los escutiformes registrados en RP 1 presentan las mismas características formales ya descriptas en un estudio específico sobre los escutiformes de Guachipas manteniendo la variabilidad en cuanto a los diseños internos (Podestá et al., 2013). Asimismo, se asume que corresponden cronológicamente a momentos posteriores al 1200 d.C. ya que se encuentran representados en artefactos como calabazas pirograbadas, placas y discos de bronce, trompetas, peines de hueso y urnas santamarianas con cronología radiocarbónica bien establecida (Aschero, 2000; López Campeny y Martel, 2014; Nastri, 2008; Nielsen, 2007; Podestá et al., 2013; entre otros).

\section{Período Incaico (1450-1535 d.C.)}

A este período corresponderían los camélidos de cola larga, delineados, que en un caso presentan indicación de autopodios. La presencia de autopodios en las extremidades de las figuras de las llamas es considerada por Berenguer, Cabello y Artigas (2007) -quienes lo documentan en sitios de la región de Tarapacá y del Alto Loa, en el Norte 

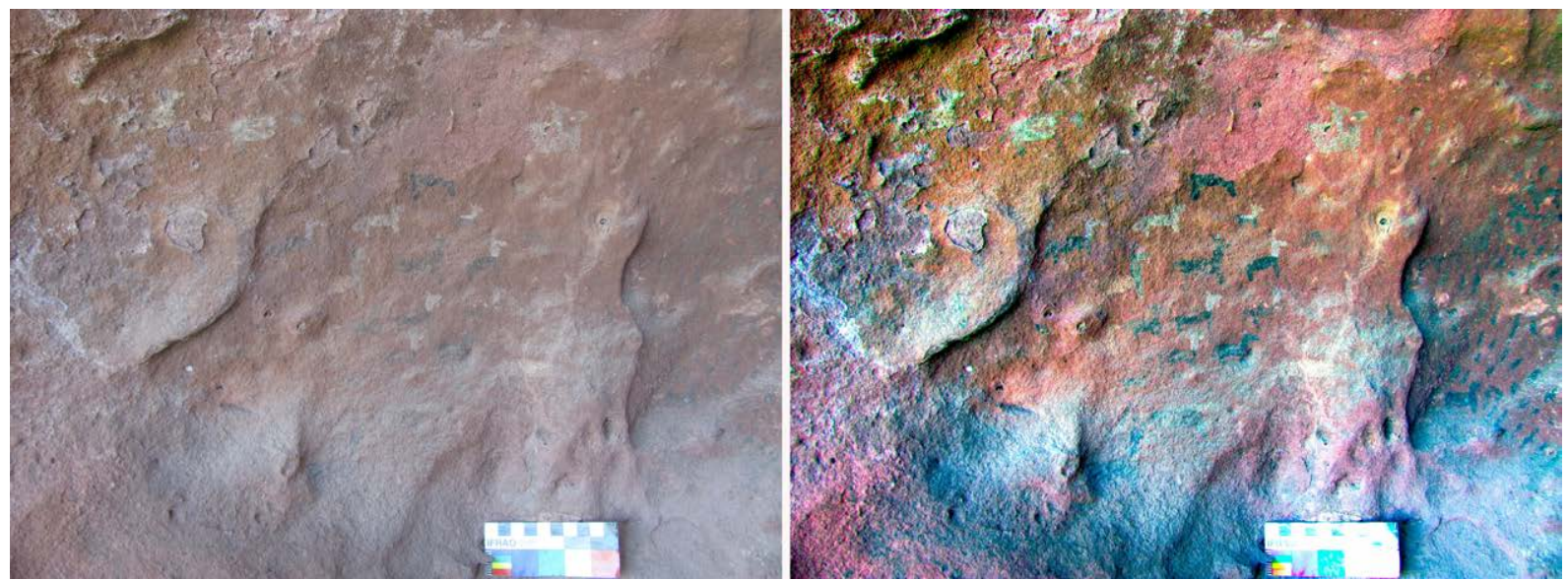

Figura 6. Camélidos agrupados asignados al periodo de Desarrollos Regionales. DStretch, canal lab.

de Chile- como típicamente incaica. Este rasgo ha sido observado en las Planchadas con la diferencia que se trata de camélidos de cuatro patas, mientras que en RP1 estas figuras solo presentan dos patas.

En RP1 se destaca la utilización de tonalidades blancas en motivos superpuestos (tres escutiformes y cuatro camélidos) a motivos de menor tamaño relativo y en varios casos de reciclados. Durante este momento se seguirían representando escutiformes, figuras humanas y camélidos pero con variaciones técnicas y morfológicas perdiendo la diversidad tonal característica del momento previo. Las tonalidades blancas y el tamaño más grande de las figuras serían utilizados con el objetivo de lograr mayor contraste y visibilidad en el soporte rocoso (Podestá et al., 2016b). Siguiendo a otros autores que ya han trabajado sobre la identificación de representaciones rupestres del período Inca, no se trataría de arte rupestre incaico sino más bien de una práctica local contemporánea a la presencia al Tawantisuyu (Berenguer, 2013; Berenguer et al., 2007; Podestá et al., 2016b). Este hecho puede abrir la posibilidad de variantes locales o modalidades regionales que se hayan desarrollado durante este período. A modo de ejemplo, los aportes de Hernández Llosas (2006) para la quebrada de Humahuaca y de Rodríguez Curletto y Angiorama (2016) para la cuenca de Pozuelos resultan sumamente valiosos para comenzar a caracterizar este arte rupestre tan discutido.

\section{Comentarios finales}

El repertorio de representaciones y conjuntos de RP 1 coincide con lo ya observado en otros sitios con arte rupestre de la microrregión Las Juntas: escutiformes, figuras humanas y camélidos, con muy bajo porcentaje de motivos abstractos para momentos tardíos; y figuras humanas, laberintos y cruces de contorno curvilíneo para momentos posiblemente relacionados con contextos del primer milenio de la era cristiana. Para el período de los Desarrollos Regionales se corrobora una vez más la estandarización de determinados motivos -escutiformes, figuras humanas y camélidos- (Aschero, 2000; López Campeny y Martel, 2014; Martel y Aschero, 2007; entre otros), mientras que para el período Incaico comienza a delinearse su caracterización (Podestá et al., 2016b; Rodríguez Curletto y Angiorama, 2016). Esta caracterización es indispensable formularla en términos regionales, cuantos más estudios se dediquen a identificar este momento en el arte rupestre más posibilidades habrá de lograr una comprensión a mayor escala. 
La superposición de escutiformes sobre camélidos esquemáticos de cuatro patas coincide con lo observado en CCP en cuanto a la existencia de un componente de arte rupestre más temprano en la zona. No tan reconocido como los escutiformes pero igualmente interesante, permite proponer la utilización continua e intensa de estos espacios por grupos humanos desde comienzos de la Era Cristiana. La presencia de cerámica gris incisa en sitios de la microrregión aporta una evidencia más en este sentido. Asimismo, esta información se suma a lo observado por Podestá y colaboradoras (2016b) en el sitio Las Planchadas con evidencias de representaciones relacionadas con momentos del periodo de Desarrollos Regionales, incaicos y de contacto hispano indígena. Es decir, nos encontramos en una localidad que empieza a mostrar evidencias como para explicar una larga secuencia de ocupación y de reutilización de soportes para la ejecución de representaciones rupestres, en la que será imprescindible identificar los cambios que fueron presentándose a lo largo del tiempo. Futuras investigaciones aportarán información imprescindible para construir esta historia.

\section{Agradecimientos}

A la Dirección de Patrimonio de la provincia de Salta y a la Municipalidad de Guachipas por su valioso apoyo durante los trabajos de campo. A los pobladores de Las Juntas, especialmente a Franco Sajama, Juan Colque, Fabricio Mansilla, Maximiliano Colque y Walter Ruiz por ser nuestros guías y ayudantes de campo. A Gimena Conforti por la confección de los mapas. A Axel Nielsen y M. Mercedes Podestá por la atenta lectura de los primeros borradores de esta propuesta. A los evaluadores quienes con sus observaciones contribuyeron a mejorar este trabajo. A la Asociación de Amigos del Instituto Nacional de Antropología por acompañarnos a lo largo tantos años. 


\section{Q Referencias citadas}

" Alonso, R. N., Navamuel, E. y Taruselli, E. (200o). Cabra Corral. Geología-ArqueologíaHistoria. Salta: Gráfica Editora.

"Ambrosetti, J. B. (1895). Las grutas pintadas y los petroglifos de la provincia de Salta. Boletín del Instituto Geográfico Argentina, XVI, 311-342.

》 Aparicio, F. De (1944). La Gruta Pintada de El Lajar (Departamento de Guachipas, provincia de Salta). Relaciones de la Sociedad Argentina de Antropología, IV, 79-83.

" Aschero, C. (1988). Pinturas rupestres, actividades y recursos naturales. En Yacobaccio, H. (Ed.), Arqueología Contemporánea Argentina (pp. 109-145). Buenos Aires: Ediciones Búsqueda.

" Aschero, C. (2000). Figuras humanas, camélidos y espacios en la interacción circumpuneña. En M. M. Podestá y M. de Hoyos (Eds.), Arte en las Rocas. Arte rupestre, menhires y piedras de colores en Argentina (pp. 15-44). Buenos Aires: Sociedad Argentina de Antropología y Amigos del Instituto Nacional de Antropología.

" Aschero, C. (2007). Iconos, huancas y complejidad en la Puna sur argentina. En A. Nielsen (Ed.), Producción y Circulación Prehispánicas de Bienes en el Sur Andino (pp.135166). Córdoba: Brujas.

"Berenguer, J. (2013). Unkus ajedrezados en el arte rupestre del sur del Tawantinsuyu: ¿la estrecha camiseta de la nueva servidumbre? En M. E. Albeck, M. Ruiz y B. Cremonte (Eds.), Las Tierras Altas del Área Centro Sur Andina entre el 1000 y el 1600 d.C. (pp. 311-352). Jujuy: EDIUNJu.

»Berenguer, J., Cabello, G. y Artigas, D. (2007). Tras la pista del inca en petroglifos paravecinales al Qhapaqñan en el Alto Loa, Norte de Chile. Chungara. Revista de Antropología Chilena, 39(1), 29-49.

» de Hoyos, M. (2012). Cuerpos imaginados. Variaciones en la representación de la figura humana en el arte rupestre de la zona valliserrana del noroeste argentino. (Tesis de Doctorado inédita), Universidad de Buenos Aires, Argentina.

" Falchi, M. P. (2016). La representación de la vara emplumada. Ceremonias y rituales en el arte rupestre de Guachipas, Salta (Argentina). En F. Oliva, A. Rocchietti y F. Solomita (Eds.), Imágenes Rupestres: lugares y regiones (pp. 209-217). Rosario: Universidad Nacional de Rosario.

" Falchi, M. P. (en prensa). Reflexiones acerca del sacrificio. Una aproximación a través del análisis del arte rupestre de sitio Ablomé 3 (Guachipas, Salta). Fragmentos del Pasado.

" Gradin, C. (1978). Algunos aspectos del análisis de las manifestaciones rupestres, Revista del Museo Provincial, 1, 120-133.

» Harman, J. (2008). Using decorrelation Stretch to enhance rock art images. Disponible en: http://www.dstretch.com/AlgorithmDescription.html (Acceso: 30 de julio de 2015).

» Hernández Llosas, M. I. (2006). Inkas y españoles a la conquista simbólica del territorio Humahuaca: sitios, motivos rupestres y apropiación cultural del paisaje. Boletín del Museo Chileno de Arte Precolombino, 11(2), 9-34.

"Ledesma, R. y Subelza, C. (2009). Alcances y limitaciones para caracterizar las ocupaciones formativas en Cafayate (Salta). Las sociedades formativas en el NOA: aportes, discusión y replanteo. Andes, 20(1), 1-25. 
» López Campeny, S. M. L. y Martel, A. (2014). La vestimenta del poder. Comparando los registros textil y rupestre en el noroeste de Argentina (siglos XIII a XV). Relaciones de la Sociedad Argentina de Antropología, XXXIX(1), 21-55.

» Martel A. y Aschero, C. (2007). Pastores en acción: imposición iconográfica vs. Autonomía temática. En A. Nielsen (Ed.), Producción y Circulación Prehispánicas de Bienes en el Sur Andino (pp. 329-350). Córdoba: Brujas.

» Munsell Color (2010). Munsell Soil Color Charts: With Genuine Munsell Color Chips. Grand Rapids, MI: Munsell Color.

" Nastri, J. (2008). La figura de las largas cejas de la iconografía Santamariana. Chamanismo, sacrificio y cosmovisión calchaquí. Boletín del Museo Chileno de Arte Precolombino, 13(1), 9-34.

» Nielsen, A. (2007). Armas significantes: tramas culturales, guerra y cambio social en el sur andino prehispánico. Boletín del Museo Chileno de Arte Precolombino, 12(1), 9-41.

»Podestá, M. M., Rolandi, D. y Sánchez Proaño, M. (2005). Arte Rupestre de Argentina Indígena. Noroeste. Buenos Aires: GAC, Academia Nacional de la Historia.

» Podestá, M. M., Rolandi, D., Santoni, M., Re, A., Falchi, M. P., Torres, M. A. y Romero, G. (2013). Poder y prestigio en los Andes Centro-Sur. Una visión a través de las pinturas de escutiformes en Guachipas (Noroeste Argentino). Boletín del Museo Chileno de Arte Precolombino, 18(2), 63-88.

»Podestá, M. M., Nielsen, A., Rolandi, D., Santoni, M., Torres, M. A., Vázquez, M. M., Mariansky, J. y Guzmán, D. (2016a). Arqueología de la localidad Cerro Cuevas Pintadas, Guachipas, Salta. Una puesta al día de las investigaciones. Actas del XIX Congreso Nacional de Arqueología Argentina, Serie Monográfica y Didáctica, 54, 149-155.

» Podestá, M. M., Re, A., Romero, G. y Rolandi, D. (2016b). El sitio Las Planchadas dentro del conjunto de pinturas rupestres de la microrregión Guachipas, Salta. En F. Oliva, A. Rocchietti y F. Solomita (Eds.), Imágenes Rupestres: lugares y regiones (pp. 231-246). Rosario: Universidad Nacional de Rosario.

»Quiroga, A. (1931). Petrografías y pictografías de Calchaquí. Buenos Aires: Universidad Nacional de Tucumán.

» Rodriguez Curletto, S. y Angiorama, C. (2016). Arte rupestre del sur de la cuenca de Pozuelos (900-1535 DC). Boletín del Museo Chileno de Arte Precolombino, 21(2), 25-46.

» Rolandi, D., Podestá, M. M., Sánchez Proaño, M. y Re, A. (2002). Procesos de deterioro y diagnóstico del grado de preservación de sitios con pinturas rupestres: el caso de Las Juntas (Guachipas, Pcia. de Salta). En F. Taboada Téllez y M. Strecker (Eds.), Documento y Registro del Arte rupestre. Contribuciones al Arte Rupestre Sudamericano 6 (pp. 94-108). La Paz: SIARB.

» Santillán, L. E. (1991). Informe preliminar “Las Juntas” (Departamento de Guachipas) presentado al Museo de Antropología de Salta. Manuscrito inédito.

» Santoni, M. y Xamena, M. (1995). Pirguas del sol. Espacios sagrados y pinturas rupestres en Guachipas, Salta, Argentina. Manuscrito inédito. 